\title{
A New Experimental Method for Determining Simultaneously True Radial Temperature Profiles of Polymer Melts under Isothermal Capillary Flow
}

\author{
Narongrit SOMBATSOMPOP and Somjate PATCHARAPHUN \\ Division of Materials Technology, School of Energy and Materials, \\ King Mongkut's University of Technology Thonburi (KMUTT), \\ Bangkok 10140, Thailand
}

(Received January 11, 2001; Accepted March 15, 2001)

KEY WORDS Temperature Measurements / Shear Heating / Polymer Melts / Temperature Sensor /

In injection moulding and extrusion processes, the temperature of the polymer melt is dependent on the amount of heat generated in the polymer caused by viscous dissipation, the heat transferred through the barrel and screw, as well as the thermal properties of the polymer melt. ${ }^{1}$ The transferred heat also effects the polymer melting behaviour, affecting the uniformity of the melt discharged from the process and its temperature. In extrusion, the melt temperature has a significant effect in the output rate of an extruder whereas melt temperature readings on the extruder are not absolute, but vary with the method of the measurement, the sensor type used, and specific conditions (such as bore diameter of dies and pressure levels). ${ }^{2,3}$ It is very essential to measure the true temperature of the polymer melt during processing. Ideally, the properties of temperature sensor used for accurate temperature measurements in polymer processing are fast response time, non-intrusive measurement capability, real time display and robust design. ${ }^{4}$ In the literature, various types and designs of temperature sensors have been introduced and used which can be categorized into the following types; Infrared (IR) probe, conventional thermocouple, optical pyrometers, ultrasonic probe, refractive index and temperature sensitive tracers. ${ }^{5}$ It should be noted that where simultaneously radial temperature profiles in the duct are required the above temperature sensors are not very effective. ${ }^{4}$

As stated earlier that the temperature readings are dependent on the method of the measurement and the type of the sensor used. This is because different methods and sensor types present different deviations in melt temperatures being measured, this concerning shear heating and heat conduction effects between the melt and the sensor. The problem related with temperature measurement results from the complex dynamic and thermal state of the system to be measured. In most cases, the presence of a temperature sensor (probe) into a flowing polymer melt can cause two significant errors in the measurements. ${ }^{6,7}$ Firstly, as a polymer melt is flowing past a stationary temperature sensor there will be a frictional heat generated at the surface of the sensor, this causing the temperature rise in the system. Secondly, there will also be a heat transfer (heat conduc- tion) between the sensor root and its tip. As a result of these errors the measured temperature $\left(T_{\mathrm{m}}\right)$ needs to be corrected, this being carried out on the basis of eq $1 .^{8}$

$$
T_{\text {true }}=T_{\mathrm{m}}+T_{\mathrm{c}}-T_{\mathrm{f}}
$$

Where $T_{\text {true }}$ is the true melt temperature, $T_{\mathrm{c}}$ is the heat conduction error, $T_{\mathrm{f}}$ is the shear heating error.

In this article, we aimed to introduce a new experimental apparatus (including design of the temperature sensor), and the experimental procedure in order to obtain the simultaneously true radial temperature profiles of PP melt under isothermal flow without the errors of $T_{\mathrm{f}}$ and $T_{\mathrm{c}}$ as stated above. Exemplary results with critical discussion were also given.

\section{EXPERIMENTAL}

\section{Material and Experimental Equipment}

The polymer used in this article was a polypropylene (PP, P-700J), supplied in granular form by Thai Polymer Propylene Co., Ltd., with a Melt Flow Rate of 16.

The experimental apparatus used for the study of the true temperatures of the flowing PP melt is shown in Figure 1, the apparatus design being similar to a conventional rheometer. ${ }^{9}$ The barrel was specially designed such that it could be opened up into two halves which were bolted together, the barrel being fitted onto the base of a AGS-500 D (SHIMADZU) tensile testing machine. The fitting of the barrel onto the tensile testing machine allowed the possibility of the extrusion using the cross-head of the tensile machine. The barrel used was $315 \mathrm{~mm}$ long and $35 \mathrm{~mm}$ in diameter. A separate die plate and a die holder were bolted to the bottom of the barrel. A circular die with L/D of 55/4 was used. A small pressure hole was located near the die entrance for pressure measurement if desired. The apparatus temperature was controlled using a Eurotherm 018 temperature controller.

The temperature sensor used in this work was specially designed based on the construction of an interconnected series of Type-K thermocouples, the thermocouple wires $\left(T_{1}\right.$ and $\left.T_{2}\right)$ being placed over each forming measuring junctions of the sensor (also in Figure 1). The 


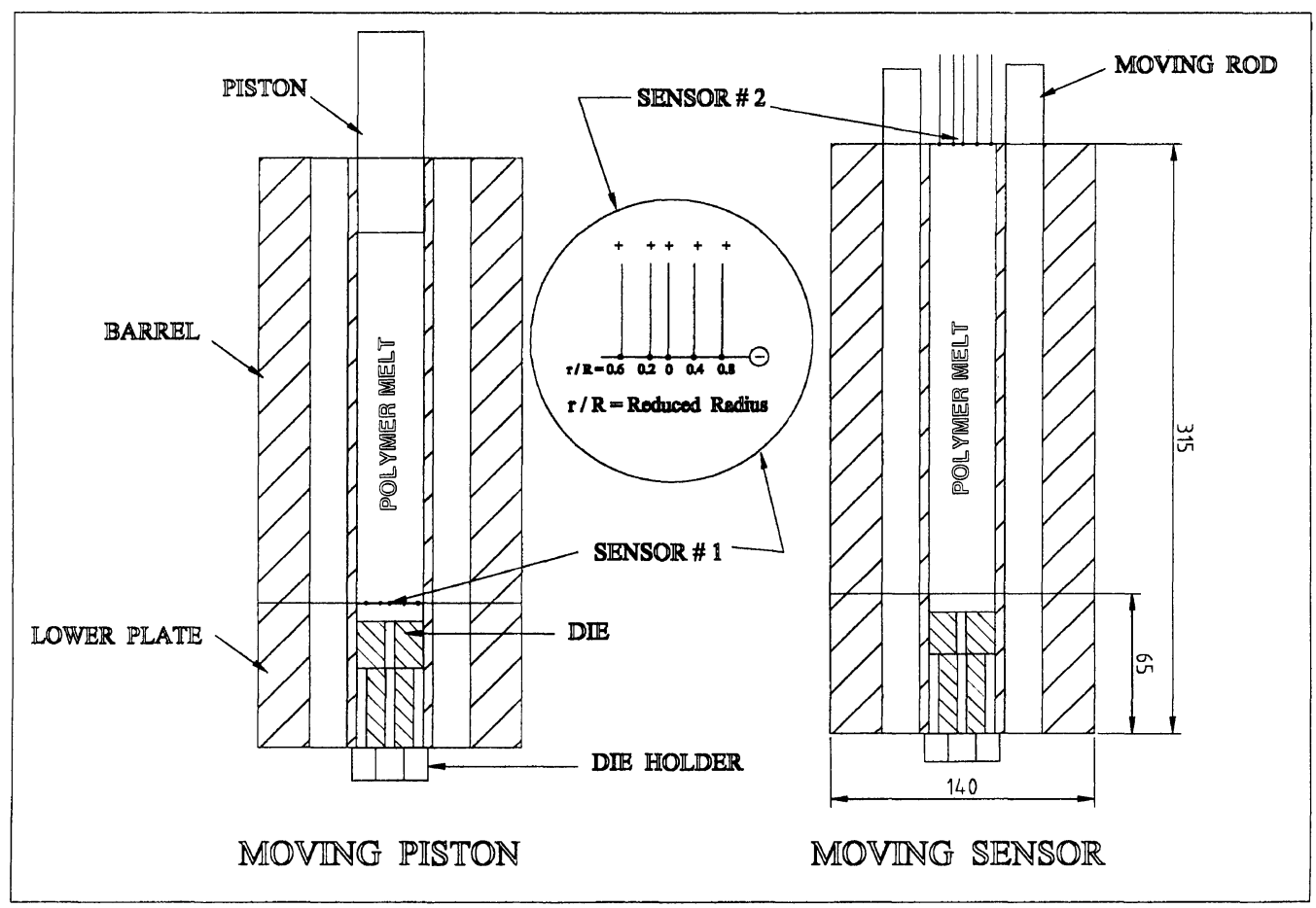

Figure 1. Experimental apparatus for temperature profile measurements (Left: moving piston mode; Right: moving sensor mode).

diameter of the wires was $0.6 \mathrm{~mm}$. The design of the temperature sensor in this work was similar to that developed by Wood et al. ${ }^{10}$ The measuring junctions were spot-welded so as to improve the mechanical strength of the measuring junctions of the sensor. It should be noted that due to the design of the sensor whose measuring junctions were directly exposed to the melt, the temperature error from the conduction effect between the sensor and the melt was automatically eliminated. Thus eq 1 was reduced to:

$$
T_{\text {true }}=T_{\mathrm{m}}-T_{\mathrm{f}}
$$

\section{Experimental Procedure}

In this work, the temperature measurements were carried out in two different ways as follows:

a) Moving piston (Figure 1-left): The melt was forced to flow past the stationary temperature sensor (sensor \#1) and through the die, which were firmly located at the bottom of the barrel by action of the piston displacement, the piston being engaged to the cross-head of the tensile tester. The sensor was positioned at 10 $\mathrm{mm}$ above the die face. The melt temperatures were recorded as a function of time (or piston displacement).

b) Moving sensor (Figure 1-right): The temperature sensor (sensor \#2) was attached to the moving rod of the apparatus which was firmly connected to the crosshead section of the tensile tester, this enabling the possibility of moving the sensor up and down along the stationary melt. In this case, the die exit was blocked. The sensor was carefully inserted so that the apparatus did not produce any leakage while moving the sensor past through the stationary melt. The melt temperatures were recorded as a function of time.
The moving piston mode gave the measured temperature $\left(T_{\mathrm{m}}\right)$ of the melt in the barrel while the moving sensor mode measured the temperature change due to the melt-sensor friction $\left(T_{\mathrm{f}}\right)$. By subtracting these two temperature results (at the same speed of the piston and sensor movements) the true melt temperature $\left(T_{\text {true }}\right)$ were produced.

The experimental procedures were commenced by allowing the apparatus to warm up and the required temperature to stabilize. The die and die holder were inserted. The barrel was charged with the polymer using a charging tool to regularly tamp down the polymer. The piston was mounted, the motor starts and the piston drive was engaged in order to compress the polymer slightly. The polymer was left in the barrel for a period of thirty minutes in order to allow the polymer to melt and consolidate, as a consequence, could be considered to have a uniform temperature, this being referred to as the isothermal condition, ${ }^{11}$ before taking the temperature measurements.

It should be noted that with the design of the sensor the temperature values are obtained simultaneously at various radial (reduced radius, $r / \mathrm{R}$ ) positions across the duct, allowing radial temperature profile to be formed. All the measurements were taken using a high-speed data acquisition system coupled to a personal computer. The test temperature (referred to as initial bulk temperature of the melt) used was in the range of 190 to $230^{\circ} \mathrm{C}$. The piston or sensor speed used was $50-500 \mathrm{~mm}$ $\min ^{-1}$.

\section{RESULTS AND DISCUSSION}

Figure 2 shows the selected temperature result for PP melt, at various radial points across the duct, as a func- 


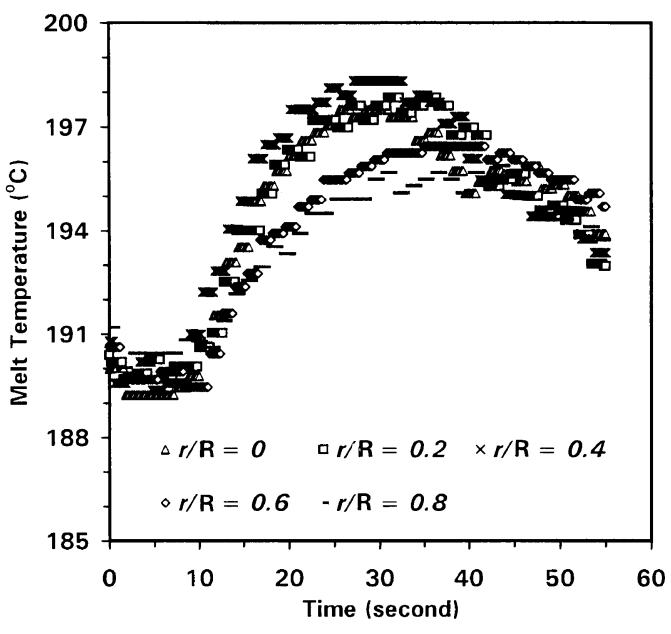

Figure 2. Temperature profiles and time for PP melt at a initial bulk temperature of $190^{\circ} \mathrm{C}$ with piston speed of $100 \mathrm{~mm} \mathrm{~min}^{-1}$ (moving piston).

tion of time using sensors \#1 (moving piston) at a piston speed of $100 \mathrm{~mm} \mathrm{~min}^{-1}$. It was found that the melt temperature for any radial position initially increased and reached a maximum before it decreased as the extrusion time proceeded. The increase in melt temperature during the flow was as a result of shear heating effect. The explanation for this behavior can be obtained in previous work. ${ }^{11}$ The maximum temperature rise $\left(\Delta T_{\max }\right)$ was approximately $8-9^{\circ} \mathrm{C}$.

The selected temperature profiles as a function of time for PP melt measured by moving the sensor \#2 past the stationary melt at a sensor speed of $100 \mathrm{~mm} \mathrm{~min}^{-1}$ is shown in Figure 3. It can be seen that the melt temperature firstly increased about $3^{\circ} \mathrm{C}$ up to $15 \mathrm{~s}$ and then stabilized. The increase in melt temperature in the initial stage was solely due to the friction between the sensor and the melt, the longer the sensor movement the higher the temperature rise. The plateau value of the temperature was caused by the fact that the maximum friction between the melt and the sensor has reached.

One interesting point to be taken into consideration was the temperature differences for each junctions. In the case of moving piston, the melt temperature around the duct center $(r / \mathrm{R}=0.0-0.6)$ was greater than that near the barrel wall, this being associated with shear heating and conduction effects and the velocity profiles whose details can be found elsewhere. ${ }^{12}$ This was not seen in the case of moving sensor, the melt temperature for each $r / \mathrm{R}$ junction being very similar. The difference between these two operation modes may probably be caused by type of velocity profiles being developed and thus shear heating during the measurements. In moving piston mode, the flow pattern of the melt was likely to be parabolic in form, ${ }^{13}$ high melt velocity around the center of the duct and low melt velocity near the barrel wall. This then resulted in relatively high shear heating (thus temperature increase) around the center. For moving sensor mode, the velocity of all the measuring junctions was the same; therefore, the shear heating was indifferent.

The temperature data from Figure 2 were re-used to obtain plots between the melt temperature as a function

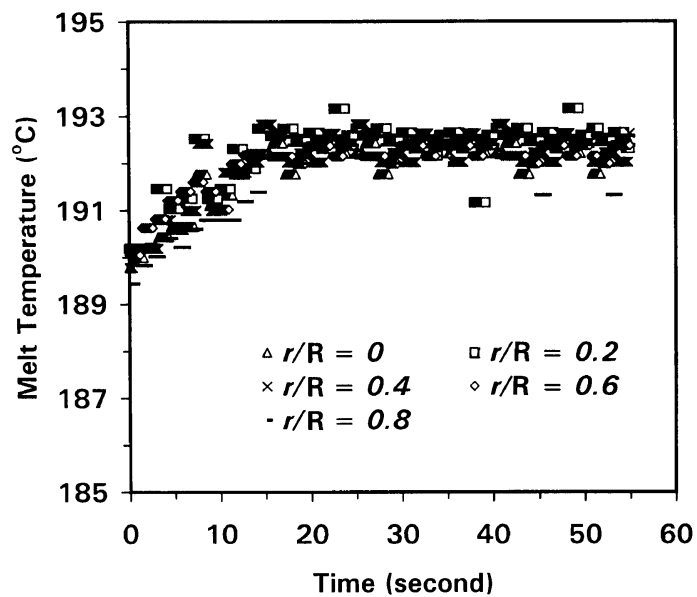

Figure 3. Temperature profiles and time for PP melt at a initial bulk temperature of $190^{\circ} \mathrm{C}$ with sensor speed of $100 \mathrm{~mm} \mathrm{~min}^{-1}$ (moving sensor).

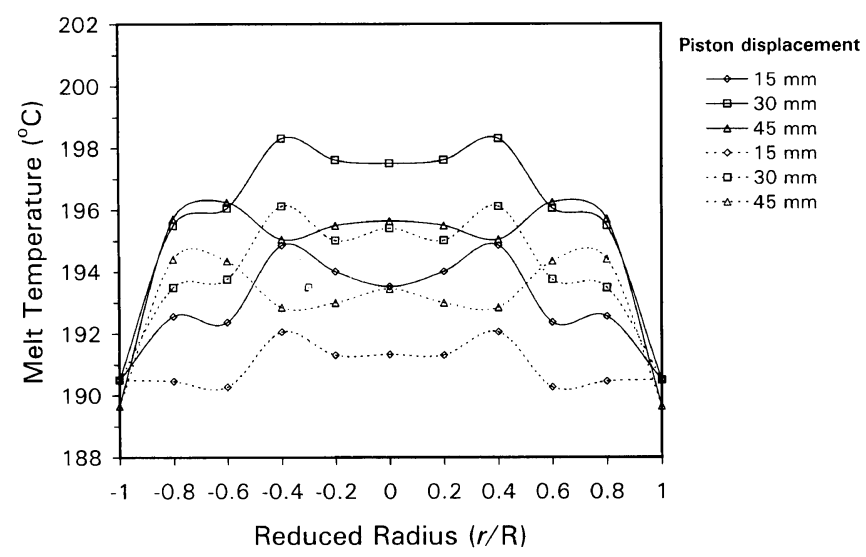

Figure 4. Uncorrected and corrected radial temperature profiles as a function of $r / \mathrm{R}$ positions for different piston displacements (Solid line: uncorrected value and Dashed line: corrected value).

of radial ( $r / \mathrm{R})$ position as shown in Figure 4, the data being presented for different piston displacements. The solid and dashed lines represent the uncorrected and corrected radial temperature profiles of the PP melt. In general, it was observed that the melt temperature profiles changed with piston displacement, the explanation for the changes in melt temperature profiles with piston displacement being given elsewhere. ${ }^{12}$ It can be seen that the corrected (true) temperature profiles was different from that of the uncorrected ones, the corrected temperature being lower than the uncorrected as one would expect.

The work was extended to study the effects of either piston or sensor speed $\left(50-500 \mathrm{~mm} \mathrm{~min}^{-1}\right)$ and initial bulk temperature $\left(190-230^{\circ} \mathrm{C}\right)$ of the melt on the $\Delta T_{\max }$ obtained from the two operation modes, the results being listed in Table I. For moving piston system, it was observed that the $\Delta T_{\max }$ initially increased with piston speed and then decreased at the higher piston speeds. The increase in the $\Delta T_{\max }$ was due to the shear heating effect whereas the decrease in $\Delta T_{\max }$ was caused by the residence time effect, the residence decreasing with increasing piston speed. Increasing initial bulk temperature from 190 to $230^{\circ} \mathrm{C}$ increased the $\Delta T_{\max }$ from 7.1 to 
Table I. Effects of piston and sensor speeds, and initial bulk temperature of the melt on $\Delta T_{\max }$ for PP melt

\begin{tabular}{|c|c|c|c|c|}
\hline $\begin{array}{l}\text { Initial bulk } \\
\text { temperature }\end{array}$ & $\begin{array}{c}\text { Piston or sensor } \\
\text { speed }\end{array}$ & $\begin{array}{c}\Delta T_{\max } \text { for } \\
\text { Moving piston } \\
\end{array}$ & $\begin{array}{l}\Delta T_{\text {max }} \text { for moving } \\
\text { sensor }\end{array}$ & $\begin{array}{c}\text { Corrected } \\
\Delta T_{\max }\end{array}$ \\
\hline${ }^{\circ} \mathrm{C}$ & $\mathrm{mm} \min ^{-1}$ & ${ }^{\circ} \mathrm{C}$ & ${ }^{\circ} \mathrm{C}$ & ${ }^{\circ} \mathrm{C}$ \\
\hline \multirow[t]{5}{*}{190} & 50 & 7.1 & 3.9 & 3.2 \\
\hline & 100 & 8.3 & 3.1 & 5.2 \\
\hline & 200 & 8.3 & 2.8 & 5.5 \\
\hline & 300 & 5.7 & 3.3 & 2.4 \\
\hline & 500 & 5.4 & 3.2 & 2.1 \\
\hline \multirow[t]{5}{*}{210} & 50 & 8.5 & 3.8 & 4.7 \\
\hline & 100 & 8.2 & 3.1 & 5.1 \\
\hline & 200 & 9.7 & 3.0 & 6.7 \\
\hline & 300 & 10.2 & 3.4 & 6.8 \\
\hline & 500 & 7.5 & 2.8 & 4.7 \\
\hline \multirow[t]{5}{*}{230} & 50 & 10.9 & 3.8 & 7.1 \\
\hline & 100 & 10.7 & 3.4 & 7.3 \\
\hline & 200 & 11.1 & 3.1 & 8.0 \\
\hline & 300 & 10.7 & 3.4 & 7.3 \\
\hline & 500 & 10.6 & 3.0 & 7.6 \\
\hline
\end{tabular}

$11.1^{\circ} \mathrm{C}$. In moving sensor system, it can be seen that the error from melt-sensor friction was so large, being in the order of $2.8-3.9^{\circ} \mathrm{C}$ which was approximated to be $30 \%$ of the measured temperature. It was interesting to observe that the changes in $\Delta T_{\max }$ was independent of sensor speed and initial bulk melt temperature. This result suggested that although the velocity of the flowing melt across the duct was different, one single correction (by moving sensor) was only required. For instance, the temperature profile at $100 \mathrm{~mm} \mathrm{~min}^{-1}$ sensor speed could be used for correcting the temperature profile generated at $100 \mathrm{~mm} \mathrm{~min}^{-1}$ piston speed (although the melt of the latter profile had different melt velocities across the duct., i.e., the melt velocity profile is usually assumed to be parabolic in nature). After correcting the $\Delta T_{\max }$ (Table I) the true $\Delta T_{\max }$ values were in the range of $2-8^{\circ} \mathrm{C}$ depending on the test speed used.

The findings in this paper had significantly practical implications in that, in order to obtain more accurate temperature value of the flowing polymer melt by insertion of the temperature probe into the melt stream, the melt-sensor friction correction had to be taken into consideration quantitatively.

\section{CONCLUSION}

This paper offered a new method of obtaining the simultaneously true radial temperature profiles of PP melt during an isothermal flow. It was found that the use of unsheathed thermocouple network and the moving of temperature sensor past the stationary melt could eliminate the conduction and shear heating errors between the temperature sensor and the polymer melt respectively. The error of the melt-sensor friction was approximated to be $30 \%$ of the measured melt temperature. Under the test conditions in this work, the true maximum melt temperature was found to be in the range of $2-8{ }^{\circ} \mathrm{C}$. Increasing the piston speed with higher initial bulk temperature of the PP melt tended to increase the true $\Delta T_{\max }$ to the optimum value, too high piston speed resulting in a decrease in the true $\Delta T_{\max }$. The polymer melt-sensor friction was found to be independent of the sensor speed and initial bulk temperature of the PP melt.

Acknowledgments. The authors would like to express our thank to the Thailand Research Fund (TRF: RSA/ 18/2543) and the National Metal and Materials Technology Centre (MTEC: MT-B-06-3D-20-306) for financial support throughout this work.

\section{REFERENCES}

1. J-F. Asassant, P. Avenas, J-Ph. Sergent, and P. J. Carreau, "Polymer Processing: Principles \& Modeling", Hansers Publishers, New York, N.Y., 1991. pp 43-47.

2. E. L. Steward, Plast. Eng., July, 39 (1985).

3. E. L. Steward, SPE ANTEC Tech. Papers, 46(1), 364 (2000).

4. N. Sombatsompop, A. K. Wood, and M. Yue, ASME Fluid Measur. Instrument., FED, 239(4), 371 (1996).

5. S. Chakravorty, C. R. S. Allen, and C. S. Brown, Polym. Test., 16(4), 455 (1997).

6. J. Van Leeuwen, Polym. Eng. Sci., April, 98 (1967).

7. H. T. Kim and E. A. Collins, Polym. Eng. Sci., 11, 83 (1971).

8. M. Hullat and W. L. Wilkinson, Plast. Rubb. Process., March, 15 (1977).

9. N. Sombatsompop, M. C. Tan, and A. K. Wood, Polym. Eng. Sci., 37(2), 270 (1997).

10. A. K. Wood, Y. H. Judeh, and M. Yue, Great Britian Patent 2291 197, (Jan. 10, 1996).

11. N. Sombatsompop and M. Panapoy, J. Mater. Sci., 35(24), $6131(2000)$

12. N. Sombatsompop and W. Chaiwattanpipat, Adv. Polym. Tech., 19(2), 79 (2000).

13. N. Sombatsompop and A. K. Wood, Polym. Eng. Sci., 37(2), 281 (1997). 